\title{
Comparison Between US Preventive Services Task Force Recommendations and Medicare Coverage
}

Lenard I. Lesser, $M D^{1}$

Alex H. Krist, MD, MPH

Douglas B. Kamerow, MD, MPH

Andrew W. Bazemore, MD, MPH

'Robert Wood Johnson Clinical Scholars Program and Department of Family Medicine, University of California, Los Angeles, Los Angeles, California

${ }^{2}$ Virginia Commonwealth University, Richmond, Virginia

${ }^{3} \mathrm{RTI}$ International, Washington, DC

${ }^{4}$ The Robert Graham Center for Policy Studies in Family Medicine and Primary Care, Washington, DC

Conflicts of interest: authors report none.

\section{CORRESPONDING AUTHOR}

Lenard I. Lesser, MD

Department of Family Medicine

University of California, Los Angeles

911 Broxton Ave, 3rd Floor

Los Angeles, CA 90049

Lesser@UCLA.edu

\begin{abstract}
PURPOSE The US Preventives Services Task Force (USPSTF) is authorized by the US government to review and disseminate the scientific evidence for clinical preventive services. The purpose of this study was to evaluate the alignment of Medicare preventive services coverage with the recommendations of the USPSTF before implementation of health reform.
\end{abstract}

METHODS We recorded all Medicare coverage for preventive services as listed in the Medicare preventive services guide of 2007 (including the 2009 update) for all recommended (A- or B-rated) USPSTF and not recommended (D-rated) guidelines for preventive screening and counseling in adults aged 65 years and older. We analyzed 2 components of preventive care: preventive coordination (risk assessment, patient motivation, and arranging of preventive service) and the preventive service itself. The main outcome measure was the percentage of agreement between USPSTF recommendations and Medicare coverage.

RESULTS The USPSTF recommended 15 preventive interventions for adults aged 65 years and older. Although Medicare partially reimbursed $93 \%$ of recommended services, full reimbursement for the preventive coordination, as well as the service, was available for only $7 \%$ of these services. This partial coverage is available mostly as part of the Welcome to Medicare Visit. Further, the USPSTF recommended against 16 preventive services; Medicare reimbursed clinicians for $44 \%$ of these services.

CONCLUSIONS Medicare coverage for preventive services needs to be reassessed, with special focus on preventive coordination. Continuing previous practices will likely promote both inadequate and excessive delivery of preventive services. The new health care reform law has the potential to improve the provision of preventive services to Medicare beneficiaries.

Ann Fam Med 2011;9:44-49. doi:10.1370/afm.1194.

\section{INTRODUCTION}

1 he Obama administration promised health reform that will "invest in prevention and wellness." ${ }^{\text {"1 }}$ One important way is to provide insurance coverage for evidence-based clinical preventive services, which have the potential to improve quality of life and prevent premature morbidity through lifestyle counseling, screening, chemoprevention, and immunization. With health care reform poised to make dramatic changes in prevention policy, it is useful to define a method for analyzing the adequacy for coverage of preventive services.

Because Medicare is the largest payer for health services for American adults, as well as the standard by which many other payers model their reimbursements for service delivery, it is a logical place to look for optimal coverage for preventive services. Preventive services were excluded from Medicare coverage when it was created in $1965 .^{2}$ Since then, though, 
Congress has amended Medicare with multiple laws to add individual preventive services. ${ }^{3}$

With the passage of the Medicare Improvement for Patients and Providers Act of 2008, ${ }^{4}$ Congress allowed the US Department of Health and Human Services (DHHS) to add preventive services to Medicare without congressional action. The law permits the secretary of the DHHS to authorize Medicare coverage for services rated A or B by the US Preventives Services Task Force (USPSTF).

The USPSTF is a government-authorized and -sponsored independent panel of experts in primary care and prevention that systematically reviews the evidence of effectiveness and develops recommendations for clinical preventive services. ${ }^{5}$ Given the evidence-based rigor of the USPSTF recommendations and that the USPSTF is mandated by federal law, a reasonable general policy would be for Medicare to cover USPSTF-recommended services. To inform new policy advancing effective prevention, we sought to compare the preventive services offered by Medicare with those recommended by the USPSTF.

\section{METHODS}

We undertook an analysis to assess a healthy senior American's access to USPSTF-recommended preventive services if he or she were solely insured through Medicare, before the implementation of the new health insurance law.

For our analysis we assumed that all beneficiaries received Medicare's version of a preventive health visit, the Welcome to Medicare Visit (WMV), even though only about $6 \%$ do. ${ }^{6}$ Although most Medicare beneficiaries are seen at least once a year for acute or chronic problems, we examined only visits for which Medicare specifically covers preventive services. Additionally, we assumed that effective preventive care included 2 components: (1) preventive coordination risk assessment, patient motivation, and arranging the service ${ }^{7}$; and (2) the preventive service testing, screening instrument, or counseling. We created this division because the USPSTF requires an evaluation of risk before applying many of their recommendations, and Medicare's preventive services guide also stipulates requirements for risk assessment. ${ }^{5,8}$ In addition, new models of care, such as the patient-centered medical home, emphasize care coordination as an essential component of the delivery of care. ${ }^{9}$ Furthermore, Medicare stresses the importance of the preventive coordination components in that they state the goals of the WMV are to "include education, counseling, and referral to screening and preventive services also covered under Medicare Part B."10

We compared USPSTF recommended and not recommended services with Medicare coverage of pre- ventive services for patients aged 65 years and older. Current USPSTF recommendations were identified using their Web site. ${ }^{5}$ All preventive services rated A (strongly recommended), B (recommended), and D (not recommended) as of May 2009 that applied to the Medicare population were included. ${ }^{11}$ Subrecommendations (eg, based on age or risk) for a preventive topic were considered independently. Services rated I (insufficient evidence) and $\mathrm{C}$ (no recommendation) were excluded, as Medicare needs to keep their coverage definitions broad to allow personal decisions on these services. Additionally, chemoprevention and immunizations were excluded, as medications are covered by Medicare through a separate mechanism (Part D) ${ }_{1}^{12}$ and the USPSTF defers to the Advisory Committee on Immunizations Practices' immunization recommendations. ${ }^{13}$ We also excluded recommendations related to sexually transmitted infections, as the incidence of these infections in the Medicare population is very low. ${ }^{14,15}$

We identified Medicare coverage policy by reviewing the 2007 Medicare preventive services guide ${ }^{10}$ and the 2009 update $^{16}$ to define covered services. We then separated coverage into the 2 preventive service delivery components: preventive coordination and the preventive service itself. For services in which the USPSTF included screening and counseling in the same recommendation, the screening portion was considered the preventive coordination and the counseling portion was considered the service delivery. This same definition of coordination and service delivery applied to such conditions as obesity, in which the coordinating part of prevention is assessing the individual and the actual service is giving the counseling.

Next, we compared Medicare coverage for both preventive service delivery components with each identified USPSTF recommendation to assess for adequate or excess coverage. We searched the Medicare preventive services guide and noted any indication that a preventive service was covered. For preventive coordination, the guide had to indicate that, as a condition of payment, some aspects of coordination (risk assessment, patient motivation, and arranging the service) were covered. The WMV satisfied conditions for preventive coordination for conditions included in the WMV, because the guide stipulates that the payment for this visit "include education, counseling, and referral to screening and preventive services."

Four categories of adequate Medicare coverage were identified: (1) fully covered-Medicare coverage for the same population at the same frequency as USPSTF recommendations $_{\text {; }}$ (2) partial coverage, WMV only-Medicare coverage for appropriate population but only during an WMV visit (ie, no coverage outside the WMV); (3) partial coverage, inconsistent indication-Medicare cov- 
Medicare reimbursed fully for the preventive coordination and the preventive service for 1 (7\%) preventive service (screening for abdominal aortic aneurysm) (Figure 1). The preventive coordination and associated screening need to be performed only once and

\section{Figure 1. Proportion of services recommended by the US Preventive Services Task Force (USPSTF) and covered by Medicare.}

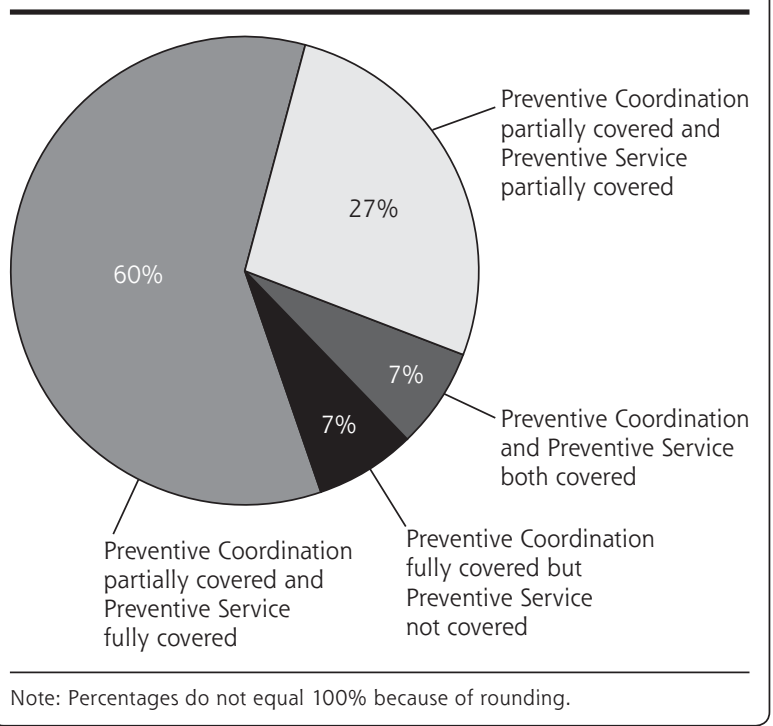

\section{Table 2. Preventive Services Covered by Medicare Which the US Preventive Services Task Force (USPSTF) Recommends Against}

\section{Preventive Screening with D Recommendation}

Medicare Coverage

Abdominal aortic aneurysm, women Yes

Asymptomatic bacteriuria No

Bladder cancer

No

Breast cancer genetic testing, not high risk

because of family history

Carotid stenosis

Cervical cancer, women $>65$ y and not at high risk, with adequate screening

Cervical cancer, women with hysterectomy

for benign disease

Colon cancer aged $>85 \mathrm{y}$

Chronic obstructive pulmonary disease

Coronary heart disease, in low-risk patients

Hemochromatosis

Ovarian cancer

Pancreatic cancer

Peripheral arterial disease

Prostate cancer, aged 75 y and older

Testicular cancer

$E C G$ = electrocardiogram; WMV = Welcome to Medicare Visit.

${ }^{a}$ Medicare covers a screening ECG as part of WMV, although it is optional.

b Specifically required as part of screening pelvic examination. is covered in conjunction with the WMV. For most preventive services (60\%), Medicare reimbursed fully for the service or test, but only partially for the coordination of obtaining that service. For 4 services (27\%) Medicare reimbursed clinicians partially for both the preventive coordination and the actual service. Finally, for 1 service $(7 \%)$, breast cancer genetic testing, Medicare reimbursed fully for the coordination and assessment (as part of risk assessment in the WMV), but not for the test or service itself (intensive counseling by a trained genetic counselor).

Most coverage for preventive coordination was included as part of the WMV. Although preventive tests were often covered beyond this visit, the risk assessment, coordination, and motivation of the patient were not.

The USPSTF recommends against 16 preventive services that would apply to Medicare beneficiaries (excluding sexually transmitted infections and immunizations against hepatitis B and C). Medicare reimbursed clinicians for 7 (44\%) of these services (Table 2). USPSTF recommendations differed based on age and frequently included ages to stop screening. Medicare, by comparison, covered services for prevention for all beneficiaries regardless of age (eg, colon, cervical, and prostate cancer screening).

The USPSTF and Medicare both recommend and covered, respectively, preventive services only for certain at-risk populations, yet there are several examples for which the 2 organizations define the atrisk population differently. For example, the USPSTF recommended screening for diabetes in those with a sustained blood pressure of 135/80 mm Hg or higher, whereas Medicare covered the services for patients with many other risk factors. In the case of breast cancer genetic testing, the USPSTF recommends women with a strong family history of breast cancer to be offered genetic counseling, whereas Medicare only covered the screening and test if the beneficiary has developed cancer herself.

\section{DISCUSSION}

Our analysis shows that Medicare covered many USPSTF recommended preventive services. A substantial disconnect was evident, however, especially in 2 areas: coordination of care, and coverage of nonrecommended services.

Congress first tried to increase coverage of preventive coordination in 2005, when it authorized the WMV, or Initial Preventive Physical Examination, which is the first time Medicare could specifically pay clinicians to coordinate prevention. In 2008, Congress tried to fix one of the problems with the WMV - that seniors could 
get a WMV only during the first 6 months of enrolling-by expanding the window to 1 year.

Despite its intent, 3 realities undermined the WMV's contributions to optimal preventive care: (1) only $6 \%$ of persons get their $\mathrm{WMV}^{6}{ }_{i}(2)$ all USPSTFrecommended services applicable to adults for the rest of their lives cannot reasonably be covered in a single visit at the age of 65 years $^{17}$; and (3), to be effective, many preventive services require periodic repetition beyond a single visit. The reasons for the low uptake of the WMV are unclear, but possible reasons are logistical issues and patients not being aware of the benefit. ${ }^{18}$

Some might argue that some of the preventive services, such as blood pressure and obesity screening, can take place during regular visits. Current fee-forservice billing practices, however, allow a provider to bill only for problems, not prevention. As any primary care physician knows, these important prevention topics often get crowded out of a busy office visit focused on multiple medical problems. For example, blood pressure measurements are to be taken with the patient sitting on in a chair, with feet on floor, after 5 minutes of rest. The measurement is then is to be repeated, with an average calculated. ${ }^{19}$ Implementing this type of screening takes considerable time and coordination.

Congress has yet again tried to fix the lack of coverage for preventive coordination with the Patient Protection and Affordability Act of 2010. ${ }^{20}$ Starting in 2011, every Medicare beneficiary will be covered for annual wellness visits, removing the time window restriction of the WMV. The final requirements of the annual wellness visit were recently published and include several components that will likely improve the coverage of preventive coordination. ${ }^{21}$

Even if there is greater coverage of an annual wellness visit, prevention will not improve if seniors have a low uptake of the benefit, as shown with the WMV. The new wellness visit will fix the problem of the low uptake of the WMV only if most seniors were not getting a WMV because of it being restricted to the first year of being an enrollee. If the reasons for low uptake are logistical issues (ie physician documentation, patient awareness), then the yearly wellness visit may not fix this problem. Alternatively, incorporating preventive coordination into regular office visits may be best way to administer prevention. If so, then a fix that relies on a fee-for-service visit may not work. An alternative strategy, such as bundled or bonus payments (such as the Physician Quality Reporting Initiative), ${ }^{22}$ may turn out to be more effective.

The other finding in our analysis was the discrepancy between covered and recommended preventive services. Instead of providing payment to clinicians for recommended preventive services, Medicare pays clinicians to provide 7 services that are not recommended, potentially increasing harm, as well as medical costs, to patients. ${ }^{23}$ Patient harms are well documented and include anxiety from false-positive test results, unnecessary follow-up tests, and unnecessary complications from subsequent testing and treatments. ${ }^{24}$ Costs include both the direct cost of the initial preventive service and the extensive downstream costs associated with nonbeneficial follow-up testing and treatments.

In 2008, Congress ceded authority to approve preventive services coverage to the DHHS, allowing Medicare to create preventive services coverage policies using the same processes they currently use to determine diagnostic testing and treatment coverage. The law did not allow Medicare coverage to drop previously authorized, but ineffective services, however.

Congress has again tried to fix this problem with the Health Care Reform Act of 2010. ${ }^{20}$ The new law reinforces the ability of the secretary of the DHHS to add services to Medicare that were not given a D rating by the USPSTF. It also authorizes the secretary to remove preventive services not given an $\mathrm{A}, \mathrm{B}, \mathrm{C}$, or I rating by the USPSTF. Although doing so could improve the agreement between USPSTF recommendations and Medicare reimbursement, it still remains to be seen how this law will be implemented. As shown previously, the secretary has had the ability to add new services since 2008, but has yet to do so.

Our study did not attempt to measure utilization rates of preventive services, and our findings do not imply that absence of Medicare payment prevents a service from being implemented or that payment for a nonindicated screening service implies support for providing the service. Even so, payment practices are well-established drivers of clinician behavior. Future research is required to better quantify the relationship between paying for prevention and utilization costs among Medicare beneficiaries.

Although the new health care reform law provides new initiatives to improve the delivery of preventive services, it is now up to Medicare to align itself with the USPSTF recommendations and usher in an era of improved quality of care through effective prevention. Congress should simultaneously increase support for research on the delivery and effectiveness of preventive services.

To read or post commentaries in response to this article, see it online at http://www.annfammed.org/cgi/content/full/9/1/44.

Key words: Medicare; USPSTF; preventive health services

Submitted March 17, 2010; submitted, revised, July 7, 2010; accepted August 23, 2010. 
Preliminary results were presented at the North American Primary Care Research Group meetings, November 16-19, 2008, Rio Grande, Puerto Rico, and November 13-17, 2010, Seattle, Washington.

Funding support: Dr Lesser started work on this project while he was a Larry A. Green Scholar at the Robert Graham Center for Policy Studies in Family Medicine and Primary Care, Washington, DC. He was partially funded by the Pisacano Leadership Foundation. He is now funded by the Robert Wood Johnson Foundation.

Disclaimer: The Pisacano Leadership Foundation and Robert Wood Johnson Foundation had no role in the design, analysis, or writing of this article. The information and opinions contained in research from the Graham Center do not necessarily reflect the views or policy of the American Academy of Family Physicians.

Acknowledgements: The authors would like to thank David Meyers, MD, and Marcel E. Salive, MD, MPH, for their comments on this manuscript.

\section{References}

1. US Department of Health and Human Services. HealthReform. Gov: About. 2009. http://www.healthreform.gov/about/index.html. Accessed Oct 24, 2009.

2. Social Security Act, 42 USC §1396y.

3. Schauffler HH. Disease prevention policy under Medicare: a historical and political analysis. Am J Prev Med. 1993;9(2):71-77.

4. Pub L No. 110-275, 122 Stat. 2494.

5. US Preventive Services Task Force. About USPSTF [Web page]. http://www.uspreventiveservicestaskforce.org/about.htm. Accessed Dec 12, 2010.

6. Medicare Preventive Services Application. Centers for Medicare and Medicaid Services. http://www.cms.gov/apps/prevserv/. Accessed Jul 6, 2010.

7. Lesser $\mathrm{LI}$, Bazemore AW. Improving the delivery of preventive services to Medicare beneficiaries. JAMA. 2009;302(24):2699-2700.

8. Centers for Medicare and Medicaid Services. Your Guide to Medicare's Preventive Services. Baltimore, MD: US Department of Health and Human Services; 2009.

9. Patient-Centered Primary Care Collaborative. Joint Principles of the Patient Centered Medical Home. 2007. http://pcpcc.net/content/ joint-principles-patient-centered-medical-home. Accessed Oct 24, 2009.

10. Centers for Medicare and Medicaid Services. The Guide to Medicare Preventive Services. 2nd ed. Baltimore, MD: US Department of Health and Human Services; 2007.

11. United States Preventive Services Task Force. Grade Definitions. http://www.uspreventiveservicestaskforce.org/uspstf/grades.htm. Accessed Dec 10, 2010.
12. US Department of Health and Human Services. Agency for Healthcare Research and Quality. Coverage PD. Centers for Medicare and Medicaid Services. http://www.ahrq.gov/clinic/uspstfix.htm. Accessed Jul 6, 2010.

13. US Department of Health and Human Services. Centers for Medicare and Medicaid Services. Prescription Drug Coverage-General Information. Schedule I. http://www.cms.hhs.gov/PrescriptionDrug CovGenln/. Accessed May 2009.

14. Sexually Transmitted Disease Surveillance 2007 Supplement, Gonococcal Isolate Surveillance Project (GISP) Annual Report 2007. Atlanta, GA; 2009.

15. Sexually Transmitted Disease Surveillance 2007 Supplement, Chlamydia Prevalence Monitoring Project Annual Report 2007. Atlanta, $\mathrm{GA} ; 2009$.

16. Department of Health and Human Services. Centers for Medicare and Medicaid Services. Expanded Benefits. http://www.cms.hhs.gov/ MLNProducts/downloads/Expanded_Benefits.pdf. Accessed Feb 5, 2009

17. Yarnall KS, Pollak KI, Østbye T, Krause KM, Michener JL. Primary care: is there enough time for prevention? Am J Public Health. 2003;93(4):635-641.

18. Petroski CA, Regan JF. Use and knowledge of the new enrollee "Welcome to Medicare" physical examination benefit. Health Care Financ Rev. 2009;30(3):71-76.

19. Chobanian AV, Bakris GL, Black HR, et al. National Heart, Lung, and Blood Institute Joint National Committee on Prevention, Detection, Evaluation, and Treatment of High Blood Pressure; National High Blood Pressure Education Program Coordinating Committee. The Seventh Report of the Joint National Committee on Prevention, Detection, Evaluation, and Treatment of High Blood Pressure: the JNC 7 report. JAMA. 2003;289(19):2560-2572.

20. Publ L No. 111-148. 124 Stat 119. Patient Protection and Affordable Care Act.

21. Department of Health $\varepsilon$ Human Services. Centers for Medicaid and Medicare Services. Medicare claims processing. Pub 100-04. http:// www.medicarefind.com/searchdetails/Transmittals/Attachments/ R2109CP.pdf. Accessed Dec 13, 2010.

22. US Department of Health and Human Services. Centers for Medicare and Medicaid Services. Physician Quality Reporting Initiative. http://www.cms.gov/pqri/. Accessed Jul 6, 2010.

23. Merenstein D, Daumit GL, Powe NR. Use and costs of nonrecommended tests during routine preventive health exams. Am J Prev Med. 2006;30(6):521-527.

24. Lin K, Lipsitz R, Miller T, Janakiraman S; U.S. Preventive Services Task Force. Benefits and harms of prostate-specific antigen screening for prostate cancer: an evidence update for the U.S. Preventive Services Task Force. Ann Intern Med. 2008;149(3):192-199. 